\title{
Increased Oxidative Stress Markers in Subjects Occupationally Exposed to Heavy Metals May Be Due to Poor Antioxidant Responses to Stressors
}

\author{
Okonkwo Francis Obiora ${ }^{1}$, Benjamin Danladi ${ }^{1}$, Bege Jonathan ${ }^{1,}$, , Uzonu Ikenna Ugonna ${ }^{2}$, \\ John Barnabas Nvau ${ }^{3}$, Chukwunonso ECC Ejike ${ }^{4}$ \\ ${ }^{1}$ Environmental \& Occupational Toxicology Unit, Department of Biochemistry, Faculty of Natural and Applied Sciences, Plateau State \\ University, Bokkos, Nigeria \\ ${ }^{2}$ Environmental Management and Toxicology Department, College of Natural Resources \& Environmental Management, Michael Okpara \\ University of Agriculture, Umudike, Umuahia, Nigeria \\ ${ }^{3}$ Department of Chemistry, Faculty of Natural and Applied Sciences, Plateau State University, Bokkos, Nigeria \\ ${ }^{4}$ Department of Medical Biochemistry, Faculty of Basic Medical Sciences, Alex Ekwueme Federal University, Ndufu-Alike, Nigeria
}

\section{Email address:}

francis.okonkwo@plasu.edu.ng (O. F. Obiora), bendanladi@gmail.com (B. Danladi), begejonathan@plasu.edu.ng (J. Bege), ijkuzonu@gmail.com (U. I. Uzonu), johnnvau5@gmail.com (J. B. Nvau), nonsoejikeece@yahoo.com (C. ECC Ejike)

${ }^{*}$ Corresponding author

\section{To cite this article:}

Okonkwo Francis Obiora, Benjamin Danladi, Bege Jonathan, Uzonu Ikenna Ugonna, John Barnabas. Nvau, Chukwunonso ECC Ejike. Increased Oxidative Stress Markers in Subjects Occupationally Exposed to Heavy Metals May Be Due to Poor Antioxidant Responses to Stressors. American Journal of Biomedical and Life Sciences. Vol. 7, No. 6, 2019, pp. 184-189. doi: 10.11648/j.ajbls.20190706.20

Received: December 5, 2019; Accepted: December 12, 2019; Published: December 23, 2019

\begin{abstract}
Artisanal miners (AM) and farmers who use water from abandoned mines for irrigation (FA) are occupationally exposed to heavy metals. Understanding their antioxidant-responses to such stressors warrants investigation. The oxidative stress levels and antioxidant-responses in 45 test subjects (AM, 30; FA, 15) and 15 control subjects who live far away from any mine (CS) were investigated. Blood concentrations of malondialdehyde (MDA) and reduced glutathione (GSH) and the activities of glutathione peroxidase (GPx), glutathione s-transferase (GST) and catalase (CAT) of the 60 subjects were determined/assayed using standard methods. Appropriate statistical tests were used to analyze the data. MDA concentrations were significantly higher $(P<0.05)$ in the AM and FA groups relative to the CS/control group. GSH concentrations, GPx and CAT activities were statistically similar $(P>0.05)$ in all groups. However, GST activity $(\mu \mathrm{mol} / \mathrm{min} / \mathrm{ml})$ was significantly reduced in the AM $(8.8 \pm 1.0)$ and FA $(8.7 \pm 0.5)$ groups compared to the CS group $(10.4 \pm 2.3)$. The inability of subjects occupationally exposed to heavy metals to increase the activity of their antioxidant enzymes and the concentration of GSH may be responsible for the heightened lipid peroxidation found in them.
\end{abstract}

Keywords: Oxidative Stress, Heavy Metal Exposure, Urinary Phenol, Artisanal Miners, Stressors

\section{Introduction}

Heavy metals are regarded as environmental pollutants due to their bio-toxicity and persistence in the environment. Anthropogenic activities such as mining and industrial processes for the extraction of mineral resources and their subsequent use for industrial, and economic development has led to an increase disturbance of the biogeochemical cycles of these heavy metals $[1,2]$. The long history of mining in the Plateau State has led to the existence of large man-made ponds containing heavy metal-contaminated water [3]. This water usually accumulates during the rainy season and lasts throughout the dry season, thereby becoming a veritable source of water for agricultural purposes. Though commercial miners have abandoned many of the mines, artisanal miners still make a living out of the abandoned mines, in ways that expose them to heavy metals and the attendant consequences. Indeed incidences such as occurred 
in the Galena mines in Zamfara State in 2010, leading to the death of scores of children [4] are still sore points in our collective memory. Residents of areas close to the mines typically grow vegetables using water from the ponds for irrigation, usually without the use of personal protective equipment such as gloves, masks, protective clothing and boots, etc.[5] These people, though not involved in direct mining, are exposed to risks as they come in contact with the heavy metals in the pond waters. Some of these heavy metals have biological as trace elements. However, the biotoxic effects of many of them in humans are of great concern. When ingested, they form stable biotoxic compounds, thereby mutilating their structures and hindering bioreactions of their functions.

The effect of these toxic metals on human health is currently an area of interest due to the ubiquity and mode of exposure. [6]

In general, bio-toxicity of metal ions to mammalians systems is due to biochemical reactions of the ions with cellular proteins, membrane system and enzymes. While antioxidant enzymes and compounds on the other hand, through intricate redox chemistry, typically protect the body against oxidative stress from metabolic activities or from xenobiotics [6, 7]. However, beyond a certain threshold, antioxidant enzymes and compounds may be overwhelmed, resulting in the oxidation of the major macromolecules proteins, lipids, and nucleic acids [8]. This nonetheless opens vistas of opportunities for intervention in those facing oxidative stressors, using exogenous antioxidants.

Given that heavy metal toxicity results in (among others) heightened oxidative stress, this study set out to determine the oxidative stress markers and antioxidant-responses of individuals exposed occupationally to heavy metals (artisanal miners and farmers using water from abandoned mines for irrigation), and compare same to those of subjects who are not so-exposed (individuals living far away from the mines).

\section{Methods}

\subsection{Study Area}

Due to her history of mining, Barkin-Ladi Local Government Area (LGA) of Plateau State Nigeria was chosen as the site for the study. Figures 1 and 2 show the map of Nigeria with Plateau State, and some pictures of the mining sites and miners at work, respectively. Eight (8) locations in Barkin-Ladi LGA were chosen for this study because of the presence of adjoining residential settlements as well as ponds serving the residents as a source of water for agricultural purposes.

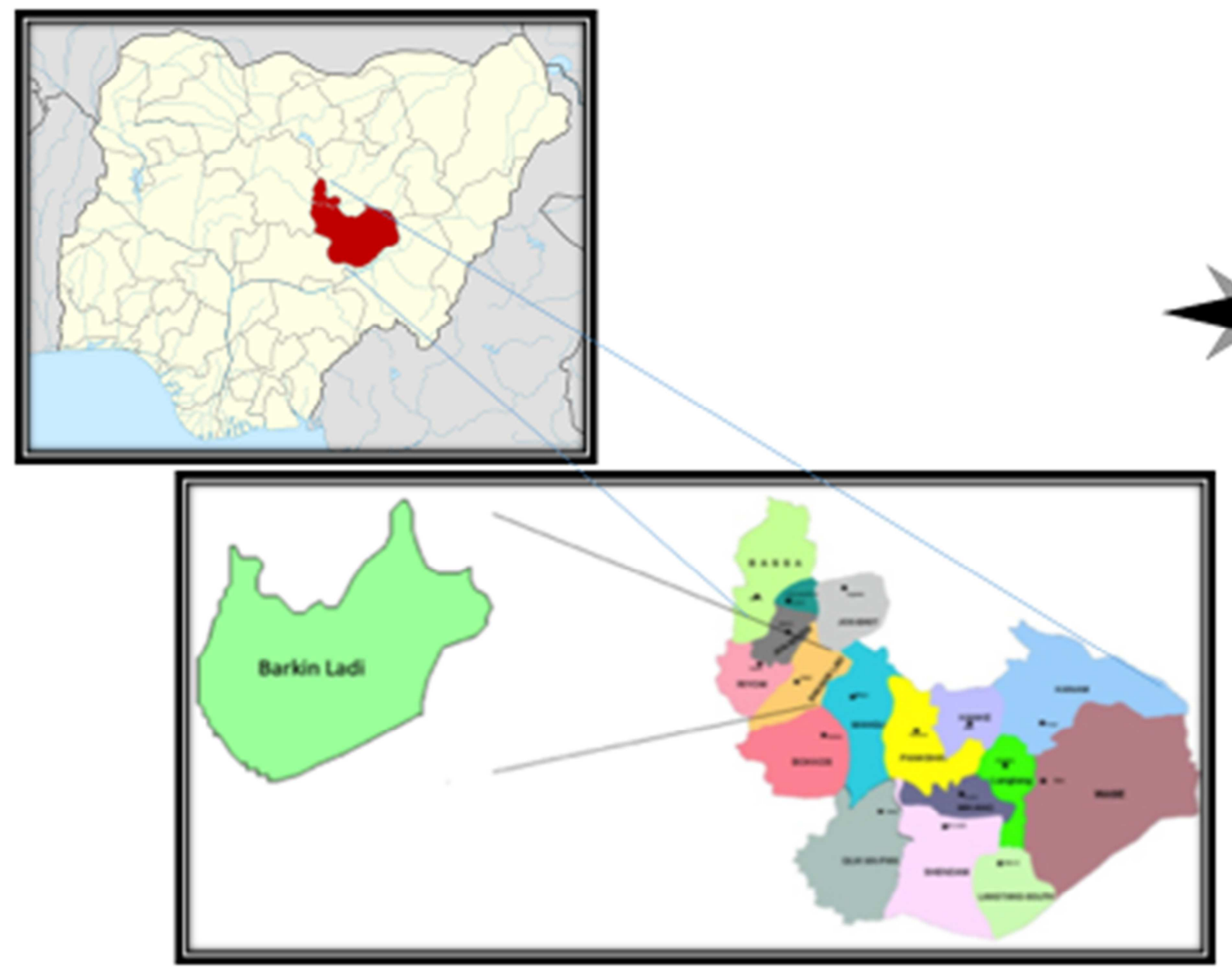

Figure 1. Map of Nigeria showing Plateau State and Barkin-Ladi Local Government Area. 


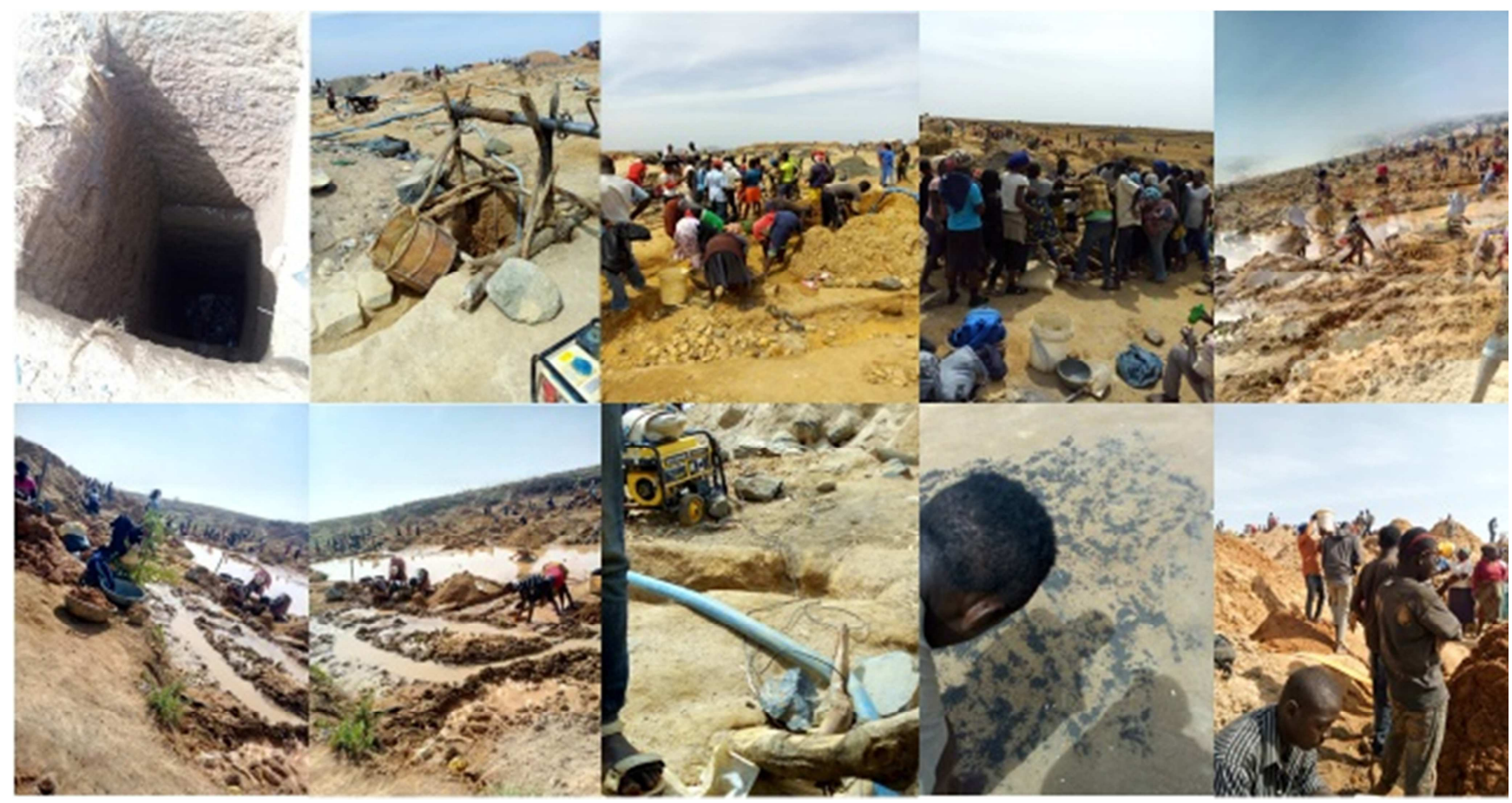

Figure 2. A collage of pictures from a typical artisanal mining site in Barkin-Ladi LGA.

\subsection{Study Population}

The study population was made up of a total of 60 participants comprising of three groups, viz: artisanal miners (AM) $(n=30)$, farmers who use water from mining ponds for irrigation (FA) $(\mathrm{n}=15)$, and control subjects who live far away from the mines (CS) $(n=15)$. The CS group were mostly staff of Plateau State University and had never been involved in mining activities. Only subjects who gave informed verbal consent were recruited for the study. They were offered free health and nutrition education as a reward for their participation.

\subsection{Sample/Data Collection}

Self-reported age (at last birthday), bio-demographic data, occupation, and smoking status were recorded per subject. Blood samples were collected from the antecubital vein of overnight-fasted subjects, into cryotubes containing EDTA. The samples were stored in ice and transported to the laboratory where they were stored at $-20^{\circ} \mathrm{C}$ until analyzed.

\subsection{Determination of Serum Oxidative Stress Markers}

The degree of lipid peroxidation in blood was determined using malondialdehyde (MDA) as a proxy for thiobarbituric acid reactive species (TBARS), following a method described by Varshney and Kale [9]. The serum concentrations of reduced glutathione (GSH), and the activities of glutathione-s-transferase (GST), glutathione peroxidase (GPx) and catalase (CAT) in serum, were determined by the methods [10-13], respectively.

Ethical clearance was sought and obtained from Plateau State Human Research Ethics Committee with reference number NHREC/05/01/2010b following which informed consent in writing was obtained from all the participants prior to the commencement of the study.

\subsection{Statistical Analysis}

The data obtained were subjected to descriptive statistical analysis and then inferential statistical analysis. The descriptive data are presented as means and standard deviations. The one-way ANOVA test was used to compare differences between means. Statistical analyses were carried out using the SAS system, version 9.4 (SAS Institute, Cary USA).

\section{Results and Discussion}

As much as $47 \%$ of subjects in the FA group were females, while $33 \%$ and $13 \%$ of those in the CS and AM groups, respectively, were males. There was no statistically significant difference $(P>0.05)$ between the mean ages of the subjects in the three groups (AM, $28 \pm 10 \mathrm{yrs}$; FA, $27 \pm$ $15 \mathrm{yrs}$; CS, $24 \pm 3 \mathrm{yrs}$ ). None of the subjects in the CS and FA groups smoked, while $37 \%$ of the AM smoked (and had been smoking for at least a year). The fact that the AM group were largely males and the lower rates of smoking among females in Nigeria may explain the fact that smokers were not present in the FA and CS groups.

The products of oxidative stress measured using MDA, a by-product of lipid peroxidation [7], indicate that members of the AM and FA groups faced significant oxidative stress. The MDA concentrations of the AM and FA groups were significantly higher $(P<0.05)$ than that of the CS group. MDA concentrations are known to be increased in heavy metal-exposed subjects compared to controls $[14,15]$. Clearly, the additional exposure of the artisanal miners (AM) 
and farmers who use polluted water in irrigation (FA), may be responsible for their higher levels of oxidative stress. Implicit in the observations is a likely overwhelming of the antioxidant defence system of the individuals. Indeed the results of the antioxidant enzymes and compound studied are telling (Figure 3).

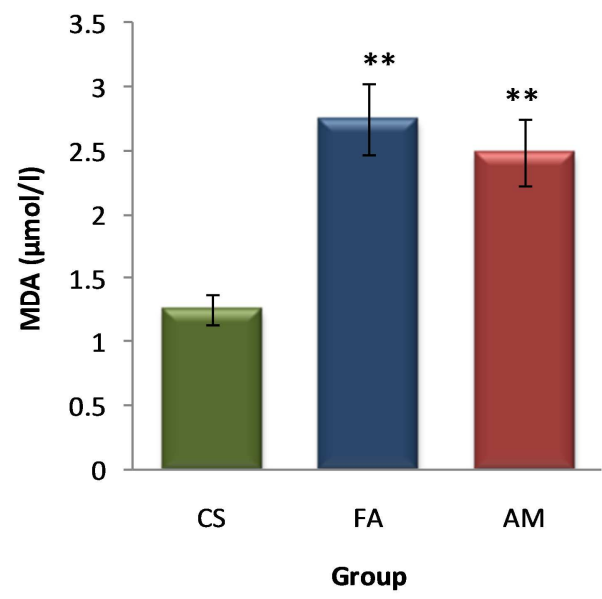

Figure 3. Malondialdehyde concentrations of subjects exposed to heavy metals occupationally or through consumption of vegetables.

CS, FA, and AM represent subjects living far away from mining sites, farmers who use heavy metal-contaminated water for irrigation, and artisanal miners, respectively. In addition to occupational exposure (FA and AM), all subjects were exposed to heavy metals possibly through the consumption of vegetables grown with heavy metalcontaminated water.
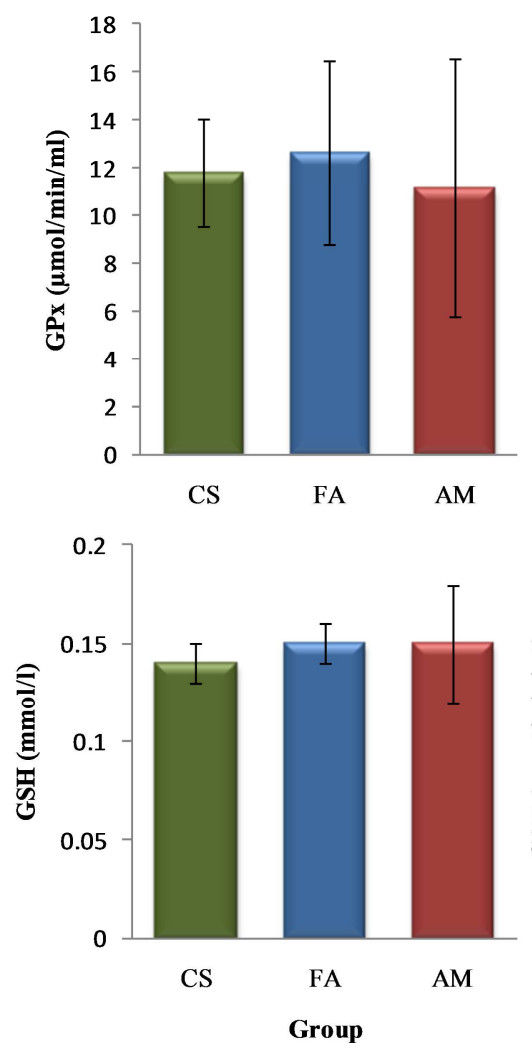

The serum GST activity was significantly $(P<0.05)$ higher in the CS group compared to the other groups [10.4 \pm $2.3 \mu \mathrm{mol} / \mathrm{min} / 1 \mathrm{Vs} 8.7 \pm 0.5 \mu \mathrm{mol} / \mathrm{min} / 1$ (FA) and $8.8 \pm 1.0$ $\mu \mathrm{mol} / \mathrm{min} / \mathrm{l}(\mathrm{AM})]$. That is, those occupationally exposed to heavy metals had reduced GST activity. The other antioxidant enzymes and compound were statistically similar $(P>0.05)$ between the groups. Therefore, whereas the AM and FA groups were exposed to heavy metals, they either had comparable or lower activities antioxidant enzymes and the antioxidant compound GSH (Figure 4).

Glutathione metabolism is one of the major and important anti-oxidant systems in the body with two key enzymes: (selenium-dependent) glutathione peroxidase (GPx, EC1.11.1.19) and (selenium-independent) glutathione-s-transferase (GST, EC2.5.1.18). Both enzymes act in association with GSH to convert hydrogen peroxide $\left(\mathrm{H}_{2} \mathrm{O}_{2}\right)$ to water [16]. The finding that there were no significant differences in GSH and the antioxidant enzyme activities studied (and indeed the increased GST activity in CS the group) may be responsible for the higher MDA concentrations in the AM and FA groups. Clearly, the inability of the AM and FA groups to counter the oxidative onslaught they faced (as would have been the case if they had higher antioxidant responses) resulted in higher oxidative damage, evidenced in higher MDA values.

Individuals occupationally exposed to heavy metals may require antioxidant supplementation to cope with the oxidative stress they daily face. Regular intake of antioxidants (even as supplements) is recommended to supplement the endogenous antioxidants of workers occupationally exposed to heavy metal-induced oxidative stress.
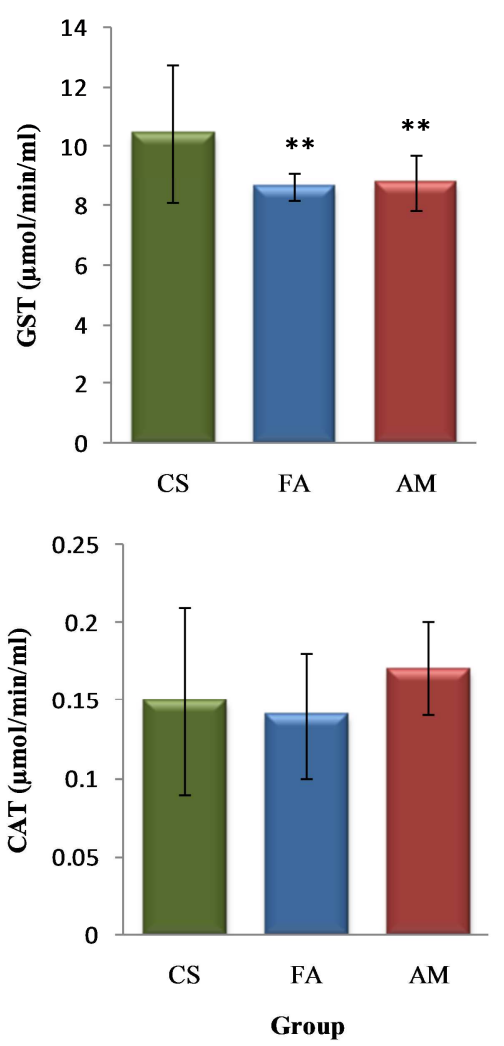

Figure 4. Antioxidant enzymes and compound of subjects exposed to heavy metals occupationally or through consumption of vegetables. 
GPx, GST, GSH, and CAT stand for glutathione peroxidase, glutathione s-transferase, reduced glutathione and catalyze, respectively. CS, FA, and AM represent subjects living far away from mining sites, farmers who use heavy metal-contaminated water for irrigation, and artisanal miners, respectively. In addition to occupational exposure (FA and AM), all subjects were exposed to heavy metals possibly through the consumption of vegetables grown with heavy metal-contaminated water. Antioxidants were measured in the blood of 60 over-night fasted subjects (AM, 30; CS, 15; FA, 15).

\section{Conclusion}

The elevated levels of oxidative stress markers confirm a potential role of oxidative stress in the molecular mechanism of the disease and aging amount the sample population. Occupational exposure to heavy metals resulted in increased oxidative stress in artisanal miners and farmers who use heavy metal-contaminated water for irrigation, probably from the inability of the individuals to increase their antioxidant responses in the face of oxidative onslaughts. Consumption of farm product from these irrigation sites and prolonged exposure to and/or accumulation of these bio-toxic agents could be the most powerful candidates. Exogenous supplementation with antioxidants is recommended in (heavy metal) occupationally exposed populations.

\section{Conflict of Interest}

All the authors do not have any possible conflicts of interest.

\section{Acknowledgements}

F.O.O received support from the Tertiary Education Trust Fund (TetFund) through its Institutional Based Research (IBR) intervention at Plateau State University, Bokkos, Nigeria.

\section{Author Contributions}

Okonkwo Francis Obiora was responsible for conception, design, supervision of the study, and contributed in writing the initial manuscript. BD was responsible for field and laboratory work, and JBN was responsible for the supervision, data presentation and proofing while CECCE contributed to the design of the study, data presentation and writing the manuscript. All authors read and approved the final version of the manuscript.

\section{Ethical Approval}

All authors hereby declare that all experiments have been examined and approved by the appropriate ethics committee and have therefore been performed in accordance with the ethical standards laid down in the 1964 Declaration of Helsinki.

\section{References}

[1] H. Ali, E. Khan, I. Ilahi, Environmental chemistry and ecotoxicology of hazardous heavy metals: environmental persistence, toxicity, and bioaccumulation, Journal of Chemistry, (2019).

[2] M. A. Ashraf, M. J. Maah, I. B. Yusoff, Study of water quality and heavy metals in soil \& water of ex-mining area Bestari Jaya, peninsular Malaysia, International Journal of Basic \& Applied Sciences IJBAS-IJENS, 10 (2010) 7-23.

[3] M. U. Henry, R. A. Ogenyi, U. Henry, O. Dogun, Assessment of heavy metal concentration in water, soil and vegetable in ex-mining pond, Jos South L. G. A., Plateau State, Nigeria., Int. J. Sci. Res. Pub, 8 (2018) 341-345.

[4] W. H. Organization, Nigeria: Mass lead poisoning from mining activities, Zamfara State, Environ Health in Emerg [Internet], (2010).

[5] F. O. Okonkwo, A. A. Njan, C. E. Ejike, U. U. Nwodo, I. N. Onwurah, Health Implications of Occupational Exposure of Butchers to Emissions from Burning Tyres, Annals of global health, 84 (2018).

[6] M. Mahurpawar, Effects of heavy metals on human health, Int. J. Res. Granthaalayah, 530 (2015) 1-7.

[7] M. Ściskalska, M. Zalewska, A. Grzelak, H. Milnerowicz, The influence of the occupational exposure to heavy metals and tobacco smoke on the selected oxidative stress markers in smelters, Biological trace element research, 159 (2014) 59-68.

[8] F. Okonkwo, C. Ejike, Simulation of heavy metal contamination of fresh water bodies: Toxic effects in the catfish and its amelioration with co-contamination with glyphosate, Journal of Applied Sciences and Environmental Management, 15 (2011).

[9] R. Varshney, R. Kale, Effects of calmodulin antagonists on radiation-induced lipid peroxidation in microsomes, International journal of radiation biology, 58 (1990) 733-743.

[10] E. Beutler, Improved method for the determination of blood glutathione, J. lab. clin. Med., 61 (1963) 882-888.

[11] W. H. Habig, M. J. Pabst, G. Fleischner, Z. Gatmaitan, I. M. Arias, W. B. Jakoby, The identity of glutathione S-transferase $\mathrm{B}$ with ligandin, a major binding protein of liver, Proceedings of the National Academy of Sciences, 71 (1974) 3879-3882.

[12] J. T. Rotruck, A. L. Pope, H. E. Ganther, A. Swanson, D. G. Hafeman, W. Hoekstra, Selenium: biochemical role as a component of glutathione peroxidase, Science, 179 (1973) 588-590.

[13] A. K. Sinha, Colorimetric assay of catalase, Analytical biochemistry, 47 (1972) 389-394.

[14] A. El Safty, L. Rashed, A. Samir, H. Teleb, Oxidative stress and arsenic exposure among copper smelters, Journal of Advances in Medicine and Medical Research, (2014) 29552968. 
[15] M. O. Islam, T. Bacchetti, G. Ferretti, Alterations of Antioxidant Enzymes and Biomarkers of Nitro-oxidative Stress in Tissues of Bladder Cancer, Oxidative medicine and cellular longevity, (2019).
[16] L. Uriah, Y. Ezekiel, O. Toochukwu, J. Jesse, Assessment of some heavy metals distribution and their possible human health risks: A case study of parts of Langtang south area, middle Benue trough, Nigeria, American Journal of Environmental Protection, 3 (2014) 54-65. 